\title{
Ego Depletion After Social Interference
}

\author{
Alex Bertrams ${ }^{1}$, Sabine Pahl ${ }^{2}$ \\ ${ }^{1}$ Department of Psychology, University of Mannheim, Mannheim, Germany \\ ${ }^{2}$ School of Psychology, University of Plymouth, Plymouth, UK \\ Email: alex.bertrams@uni-mannheim.de
}

Received November $11^{\text {th }}, 2013$; revised December $9^{\text {th }}, 2013$; accepted January $2^{\text {nd }}, 2014$

\begin{abstract}
Copyright (C) 2014 Alex Bertrams, Sabine Pahl. This is an open access article distributed under the Creative Commons Attribution License, which permits unrestricted use, distribution, and reproduction in any medium, provided the original work is properly cited. In accordance of the Creative Commons Attribution License all Copyrights (C) 2014 are reserved for SCIRP and the owner of the intellectual property Alex Bertrams, Sabine Pahl. All Copyright (C) 2014 are guarded by law and by SCIRP as a guardian.
\end{abstract}

The present study examines whether social interference (i.e., interference with one's goal attainment by the bodily presence of others) depletes the limited resource of self-control strength. In an experimental laboratory study $(N=34)$, half the participants experienced social interference whereas the other half did not experience social interference by two confederates during a dexterity task. Afterwards, we measured participants' momentary self-control strength applying a Stroop colour-naming task. In line with our prediction, participants' performance in the Stroop task indicated that social interference reduced self-control strength. We discuss implications for crowding research and crowding in natural settings.

Keywords: Crowding; Ego Depletion; Self-Control; Self-Regulation

\section{Introduction}

The presence of other people frequently interferes with individual goals: In crowded pedestrian zones, other people may walk in front, stand in the way, or walk across one's projected path; in busy supermarkets, other people may block access to shelves containing desired goods. When this happens, individuals are forced to coordinate their own movement with that of others, make avoidance movements, adjust their speed, or wait. This may be exhausting, especially when it interferes with the completion of goals (e.g., keeping an appointment or quickly doing the shopping). The present research aims to show that adaptation to such social interference is associated with selfregulatory costs. We assume that social interference requires self-control and, therefore, depletes the resource underlying self-control, which in turn is expected to lead to reduced performance in subsequent self-control demands.

Our conceptualisation of social interference is based on Schopler and Stockdale's (1977) definition of social interference in crowding: "The presence of others is interfering whenever they restrict, disrupt, or block goal-oriented response sequences” (p. 82). Emanating from this early definition, in the present work we perceive social interference as an immediate interference with a person's goal attainment by the bodily presence of other persons. In particular, we focus on the case in which others physically block individuals' moving paths with their bodies, thereby impairing individuals in moving from place A to place B (i.e., attainment of a physical goal). Such interference with a physical goal may often be related to interference with a psychological goal; for instance, when a person who is in a hurry to keep an important appointment is slowed down by others in a crowded pedestrian zone. Social interference, as we conceptualise it, is primarily characterised by physical interaction in contrast to psychological interaction:
Someone can block another person's way (physical interaction) without noticing it, so that communication between the two persons (psychological interaction) does not take place. Particularly in cities, social interference may be an integral part of everyday life (e.g., in pedestrian zones, in shops, and in railway stations).

We offer a new perspective to the phenomenon of social interference by analysing it in light of an established self-control model (Baumeister, Vohs, \& Tice, 2007; Muraven \& Baumeister, 2000). Self-control means the overriding, or inhibition, of one's own automatic, habitual, or innate behavioural tendencies in order to pursue long-term goals or to act in line with standards such as social norms (e.g., Baumeister et al., 2007; Muraven \& Baumeister, 2000). In other words, self-control enables people to alter their predominant responses in service of higher goals instead of acting on the spur of the moment. For instance, if a person's goal is to lose weight (a higher goal), that person has to suppress naturally occurring eating impulses (self-control). Lack of self-control implies impulsive behaviour (e.g., eating chocolate) and impedes longer term goal fulfilment (e.g., losing weight).

In the past years, a strength model explaining when and why self-control succeeds or fails has received a great deal of attention and has been empirically confirmed in various experiments (for reviews, see Baumeister, 2002; Baumeister et al., 2007; Muraven \& Baumeister, 2000). According to the strength model of self-control, exertion of self-control depletes a limited strength resource required for the successful exertion of selfcontrol. Therefore, individuals who have recently used this resource subsequently have less self-control strength available (a state coined ego depletion) compared to individuals who have not recently exerted self-control; thus, the former are less successful in exerting self-control than the latter. Potential alternative explanations, such as differences in mood or self- 
efficacy, do not seem to be responsible for this depletion effect (Muraven, Tice, \& Baumeister, 1998; Wallace \& Baumeister, 2002). An important aspect of the strength model is that different kinds of self-control are assumed to rely on the same strength resource, even if the required behaviours are in widely different domains. For instance, participants who were asked to suppress a certain thought were subsequently less successful in suppressing their emotional expressions compared to participants who were not initially asked to control their thoughts (Muraven et al., 1998: Study 3). Experimentally varying the self-control demands for participants in an initial task and then assessing participants' self-control performance in a second task has become the basic approach for the examination of the determinants and consequences of momentarily available selfcontrol strength (Baumeister et al., 2007).

Although initially focusing on intra-personal events, several studies in the last years have examined how interpersonal events affect self-control. Some of these studies examined the effects of a lack of social interaction. For instance, Baumeister, DeWall, Ciarocco, and Twenge (2005) found that social exclusion caused decrements in self-control. In their study, people who were informed that no one wanted to work with them later ate twice as many chocolate cookies than participants who had not been rejected. However, the other extreme of social interaction-too much contact or input, such as the kind of social interference we experience in shopping malls or in crowded pedestrian zones-might also have detrimental effects on selfcontrol.

Much earlier, Glass and Singer (1972) came up with the idea that adaptation to the physical environment can have "psychic costs". In their laboratory experiments, participants who were exposed to uncontrollable noise showed decreased performance in subsequent tasks that were akin to current measures of self-control (e.g., persistence and overriding of impulses to quit during a frustrating task; see Baumeister et al., 2007). Glass and Singer interpreted their results as evidence that adaptation to uncontrollable circumstances requires psychic resources that will be missing in subsequent tasks. This interpretation is in line with the more recent strength model of self-control (Baumeister et al., 2007; Muraven \& Baumeister, 2000), in which such psychic costs are referred to as depleted self-control strength. Similar to the noise in Glass and Singer's work, social interference may be seen as uncontrollable since normally it may be difficult, if not impossible, to control how other persons will move (e.g., in a shop or a pedestrian zone). Hence, we assume that exposure to social interference, similar to exposure to uncontrollable noise, will cause decrements in subsequent self-control by depleting self-control strength.

But why is it that social interference supposedly impairs self-control? In social interference situations, a person's goaldirected movements are interfered with and, therefore, need to be adjusted. This adjustment involves the overriding of originally intended responses (i.e., self-control), such as altering intended movements (deviating from the direct path, slowing one's movements down) or suppressing intended movements (waiting) in order to avoid colliding with other persons. Thus, exposure to social interference should tax the limited resource of self-control strength, which should result in less self-control strength for later use. If people faced with social interference did not exert self-control by adjusting their movements, quite often they would find themselves in violation of social norms (e.g., colliding with others), which is generally undesirable.
Indirect evidence that social interference may impair selfcontrol stems from Heller, Groff, and Solomon (1977). They experimentally manipulated spatial density as well as the demand to move about the lab while performing tasks, such as sorting pages in a booklet and adding up numbers. When participants were in a dense situation and had to move about to perform the tasks (i.e., physical interaction was high and interfered with the task goals), they showed decreased performance during the tasks. One possible explanation of this finding might be that dealing with social interference in this condition depleted participants' self-control strength, which, as a result, negatively affected their self-control of thoughts and attention (i.e., concentration; see Baumeister, Heatherton, \& Tice, 1994). However, no direct evidence of this explanation is available to date. In a field study along the lines of Heller et al.'s laboratory experiment, Langer and Saegert (1977) asked participants to move through a busy versus a non-busy department store while performing a complex cognitive-behavioural task requiring concentration. In relation to the comparison group, participants who moved through the busy environment experienced more people obstructing their way while they tried to perform the task; that is, they experienced more social interference. These participants also performed worse than the participants in the comparison group. Again, one potential explanation for the lowered performance might be that dealing with the demands of social interference led to depletion of self-control strength.

Although Heller et al.'s (1977) as well as Langer and Saegert's (1977) findings are compatible with our assumption that social interference has adverse effects on self-control, they do not constitute sufficient evidence. Because the tasks were performed during the experience of social interference in supposedly highly sensory-demanding environments, increased cognitive load rather than reduced self-control strength might have impaired performance in these tasks. Theoretically, a key difference between the self-control model and cognitive capacity models is that self-control depletion lasts beyond the situation and can be measured after the concurrent cognitive demands have ceased (Muraven et al., 1998). Therefore, it would be desirable to test whether effects on task performance last even after the social interaction. There is one set of studies that has applied the strength model of self-control to test the after-effects of social interactions (Finkel et al., 2006). Finkel et al. found that poorly coordinated interactions that required additional adjustment beyond the actual task participants were working on with a confederate subsequently caused poorer self-control. However, this study examined interaction tasks jointly performed by two individuals (e.g., entering data together, navigating a computer maze) rather than the effects of physical blocking outside of direct interactions. Thus, Finkel et al. examined a kind of social interaction quite different from our conceptualisation of social interference. We focus more on the observation that people are also moving objects in space and that, as such, they can block one others' paths.

In sum, there is evidence that adaptation to an uncontrollable physical environment (here: uncontrollable noise) subsequently leads to poorer self-control (Glass \& Singer, 1972), that social interference has detrimental effects on performance in tasks that involve self-control (Heller et al., 1977; Langer \& Saegert, 1977), and that social interactions which require adjustment impair subsequent self-control by reducing self-control strength (Finkel et al., 2006). Up to now, however, no study exists that has shown detrimental effects of social interference on self- 
control after the interference situation has ended, thus ruling out a cognitive capacity explanation. So, in the present study, we aimed to directly test the hypothesis of whether social interference depletes self-control strength.

We conducted an experimental laboratory study in which participants engaged in a task (filling a jug with water using a spoon) while experiencing or not experiencing social interference through two confederates. Afterwards, we used response latencies in a Stroop task (Stroop, 1935) to measure momentarily available self-control strength, as in previous studies (e.g., Richeson \& Shelton, 2003): Participants were asked to name the print colours of non-corresponding colour words (e.g., the word BLUE printed in yellow). This requires participants to suppress the highly automated response to read the words and replace it by naming the printed colours instead; that is, participants have to exert self-control. Performance in the Stroop task should therefore be impaired if self-control strength has previously been depleted. We expected that participants in the social interference condition would have longer response latencies for completing the Stroop task than participants in the control condition who had not experienced social interference. This pattern would indicate that dealing with social interference has costs in terms of the depletion of self-control strength.

\section{Method}

\section{Participants and Design}

The sample included 34 undergraduates enrolled at a university in Southern Germany (28 females, mean age $=23.8$ ). We excluded three additional participants from analyses who expressed severe doubts about the cover story and one who exhibited extremely low motivation to follow the instructions (reported by the confederates and the participant himself); however, the same pattern of results emerged when these participants were included. All students participated voluntarily and received chocolate as a reward. The participants were randomly assigned to two conditions: In the experimental condition $(n=$ 18), their movements were systematically obstructed by two female confederates (social interference); in the control condition $(n=16)$, their movements were not obstructed (no social interference).

\section{Materials and Procedure}

The students were asked to participate in a study concerning the interplay between cognition and coordination. Participants were tested individually (together with the two confederates) in sessions lasting approximately twenty minutes. Upon arrival to the laboratory, participants were told that the study involved groups of three people. The confederates were placed standing in different corners of the room and appeared to be unknown to each other (one was looking through her diary; the other was busy with her mobile phone).

Next the experimenter presented the cover story, which stated that recent neuropsychological studies had found close connections between brain areas responsible for body coordination and fluid intelligence, and that this relation could be tested using behavioural measures. Ostensibly, a formula had been developed to assess fluid intelligence through performance in an unpractised dexterity task, with the aim of collecting data on this relation. The experimenter emphasised the importance of fluid intelligence for academic success in order to make the task more relevant for the participants.

After this, the task was explained. Participant and confederates were instructed to fill a spoon with water at a sink within the laboratory room and to balance until its contents were delivered to an individually assigned jug. They were told to repeat this procedure until the experimenter returned. The experimenter pointed out that the amount of water in the jug would become the numerical value to be entered into the fluid intelligence formula (a measuring container and a funnel were visibly placed in the room). Participant and confederates were also instructed not to speak during the task (cf. Heller et al., 1977). After the instructions, the experimenter gave the start signal and immediately left the room. The reason why the experimenter was not present during this phase of the experiment was to give participants in the social interference condition no possibility to complain to the experimenter (e.g., about the confederates' behaviour).

The manipulation of the independent variable took place during the dexterity task. The direct path between sink and jugs was narrow due to tables standing sideways, allowing only one person through at a time. In the social interference condition, the confederates used this path exclusively so that the fastest way was systematically obstructed for the participant, forcing the participant to regularly adjust his or her movement (i.e., stop and wait, step aside). Furthermore, the confederates positioned themselves near the sink at the beginning of the task. Therefore, the confederates were faster to the sink than the participant for the first time they filled their spoons; as a consequence, the participant's access to the sink was frequently blocked during the course of the task, so that the participant had to repeatedly interrupt the intended goal-directed movement and wait. In contrast, in the control condition the confederates took a longer route around the tables so that they did not interfere with the participant's movements. In addition, they surreptitiously arranged their speed so that they arrived at the sink after the participant; thus, the participant did not have to wait.

After five minutes, the experimenter returned and interrupted the activity. The experimenter announced that another measure had to be taken individually and asked the participant to be tested first. The confederates were asked to wait in a room next to the lab. The participant then received 280 incongruent Stroop stimuli on paper (i.e. the word did not correspond to the colour in which it was printed, e.g., the word BLUE was printed in yellow). We used blue, green, red, and yellow as colour words as well as print colours. This task was introduced to the participant as a measure of mental flexibility and the participant was instructed to name aloud the print colours of the words as fast as possible while avoiding any mistakes. The time the participant took to name all Stroop stimuli and the number of mistakes made was recorded by the experimenter.

Afterwards, the participant rated the perceived interference during the dexterity task on two items ("How much did the other participants obstruct you with attaining the task goal?", "How often were the other participants standing in your way?"). On one-item measures, they also rated the amount of effort invested in the dexterity task as well as in the Stroop task, the personal importance of performing well in each of these tasks, the amount of frustration that was experienced during the dexterity task, and the extent of negative feelings that were experienced towards the confederates. All these ratings were made on 7-point Likert scales. Finally, the participants were thanked, probed for suspicion, rewarded, and debriefed. Also each con- 
federate rated on one-item measures how much the participant was obstructed as well as how motivated, how frustrated, and how aggressive the participant appeared during the dexterity task on 6-point Likert scales. Participant and confederate ratings were coded such that higher scores indicated higher values of the respective variable. The confederates' ratings for each participant were averaged across both confederates.

\section{Results}

\section{Manipulation Check}

For the comparisons of means between the two experimental groups, we applied independent-samples t-tests. Since the participants' two ratings on perceived interference were highly correlated, $r=.83, p<.001$, we averaged them. Both participants $(M=5.11, S D=1.55$ vs. $M=2.56, S D=1.46), t(32)=$ 4.92, $p<.001, d=1.69$ and confederates $(M=5.61, S D=0.74$ vs. $M=1.22, S D=0.26), t(32)=22.57, p<.001, d=7.73$ reported more perceived social interference in the social interference condition than in the control condition. Participants also transported less water to the jug in the social interference condition than in the control condition $(M=83.17 \mathrm{ml}, S D=15.50$ vs. $M=153.88 \mathrm{ml}, S D=28.22), t(32)=-9.20, p<.001, d=$ -3.16 . Altogether, these findings indicate that the social interference manipulation was successful.

\section{Stroop Performance}

We conducted an independent-samples t-test with the experimental condition (social interference vs. no social interference) as an independent variable and time required for completing the Stroop task as a dependent variable. As expected, participants who had experienced social interference during the dexterity task took statistically significantly longer in the Stroop task $(M=310.28 \mathrm{~s}, S D=59.75 \mathrm{~s})$ than participants who had not experienced social interference $(M=264.88 \mathrm{~s}, S D=$ $40.53 \mathrm{~s}), t(32)=2.56, p=.02, d=0.88$. Participants in the social interference condition took, on average, $45 \mathrm{sec}$. longer to complete the Stroop task than participants in the control condition without social interference. The number of errors made in the Stroop task did not differ between conditions, $t(32)<1$. Thus, a speed-accuracy trade-off cannot account for the finding on time required for completing the Stroop task.

\section{Supplementary Analyses}

There were no differences between experimental conditions regarding participants' ratings of invested effort and importance of performance in the dexterity task or in the Stroop task, and the confederate ratings of participants' motivation or aggression during the dexterity task ( $p s>.25$ ). Ratings of the personal importance of performance in the dexterity task were high $(M=$ $6.00, S D=0.84$ in the social interference condition; $M=6.06$, $S D=0.93$ in the no social interference condition; maximum possible score $=7.00$ ), indicating that participants in both experimental conditions were motivated to achieve the goal during the dexterity task.

Participants in the social interference condition did not rate the dexterity task as being more frustrating than did participants in the control condition, $t(32)<1$. However, the confederates perceived the participants in the social interference condition as more frustrated $(M=1.47, S D=0.70)$ than the participants in the control condition $(M=1.03, S D=0.13), t(32)=2.50, p$ $=.02, d=0.85$. Moreover, participants in the social interference condition tended to report more negative feelings towards the confederates $(M=3.22, S D=1.70)$ than did participants in the control condition $(M=2.31, S D=1.35), t(32)=1.71, p=.10, d$ $=0.59$. Neither participants' frustration as perceived by the confederates, $r=.17, p=.34$, nor participants' negative feelings towards the confederates $r=-.01, p=.94$ correlated with the time participants took to complete the Stroop task. Thus, the performance decrements in the social interference condition were not attributable to these variables.

\section{Discussion}

The present research aimed to demonstrate that exposure to social interference reduces self-control strength and, hence, impairs subsequent self-control. In our study, the goal-directed movements of one group of participants were obstructed by the physical presence of two confederates (i.e., social interference), forcing them to adjust their intended movements. Such adjustment was assumed to involve self-control and to consume self-control strength that would subsequently be lacking in later self-control demands. We found that participants who experienced this social interference during a dexterity task took longer in a subsequent Stroop colour-naming task than participants who did not experience social interference. This finding was not attributable to a speed-accuracy trade-off as well as participants' task motivation, feelings of frustration, or negative affect towards the confederates. Since response latencies in the Stroop task have been shown to depend on self-control strength (e.g., Richeson \& Shelton, 2003), our study provides initial evidence for the assumption that social interference draws on the resource necessary for successful self-control, indicating that exposure to social interference can cause decrements in self-control.

On the one hand, our findings may provide a novel theoretical explanation of crowding effects. Prior to our study, no direct evidence was available that self-control might be taxed by crowding. Since social interference has been argued to be central in crowding (Schopler \& Stockdale, 1977), the present findings suggest that it may be worthwhile to investigate self-control processes further, as an explanation of observed effects of crowding. As we have already mentioned in the introduction, Heller et al.'s (1977) as well as Langer and Saegert's (1977) findings on reduced task performance in crowded situations may, at least in part, be determined by diminished selfcontrol strength stemming from exposure to social interference. Further evidence that effects of crowding may be attributed to reduced self-control strength comes from studies on helping behaviour: A recent study that was theoretically based on the strength model of self-control demonstrated that initial depletion of self-control strength subsequently decreased participants' willingness to help others (DeWall, Baumeister, Gailliot, \& Maner, 2008). This corresponds to a finding in the crowding literature that participants who had experienced a crowded situation were less helpful to someone in need than were participants who had experienced a less crowded situation (Cohen \& Spacapan, 1978).

On the other hand, the present research extends self-control research, particularly with reference to the important questions of why and when people fail in self-control. Extending evidence on the adverse effects on self-control after social exclusion 
(Baumeister et al., 2005), positive self-presentation (Vohs, Baumeister, \& Ciarocco, 2005), or poorly coordinated dyadic conversation (Finkel et al., 2006), social interference seems to tax self-control resources as well. So, our study provides a new piece to the mosaic that makes up the costly demands of social life.

One central limitation of the present study is its lack of external validity, which is typical for laboratory experiments. Participants were confronted with an artificial setting that was different from natural situations in which social interference may occur. Therefore it cannot be excluded that the decrement in Stroop performance was caused by characteristics specific to the circumstances in our investigation. It might be possible, for instance, that the adjustment of movements is much more automatic in natural settings, such as in a pedestrian zone, than during an unfamiliar dexterity task in a lab room. That is, since exertion of automatic behaviours should not require self-control (Muraven \& Baumeister, 2000), social interference would not lead to diminished self-control strength outside the laboratory. However, the field study by Langer and Saegert (1977) we mentioned in the introduction indicates that social interference can impair performance in complex tasks, even in natural settings. Although Langer and Saegert's study does not provide sufficient evidence to confirm our specific self-control hypothesis, it gives us some confidence that social interference may have adverse after-effects on self-control in real-life situations. Still, one important avenue for future research when following up on our initial findings would be to apply the present approach to more natural settings.

What implications can be drawn from the results? Basically, after the experience of social interference, people should be more likely to fail in self-control. There are numerous examples in every-day life in which this may matter. For instance, exposure to social interference in a shopping mall could potentially lead to impulse buying. Vohs and Faber (2007) demonstrated that participants whose self-control strength had recently been depleted felt stronger urges to buy, were willing to spend more money, and actually spent more money compared to participant whose self-control strength was intact. Hence, crowded shopping malls, in which social interference is quite likely to occur, might contribute to higher spending. Since the ability to resist other temptations such as delicious but unhealthy food (Baumeister, Bratslavsky, Muraven, \& Tice, 1998) or alcohol (Muraven, Collins, \& Nienhaus, 2002) also relies on the momentary availability of self-control strength, people are supposed to be more likely to give in to these temptations after social interference. Many temptations (e.g., fast food, candies, beer) are easily available in pedestrian zones and shopping malls, and unfortunately these places are frequently crowded. Future research could also try to expand the scope of the social interference-self-control relationship to traffic congestion. In key aspects, driving a car through the city during rush hour provides a similar interference situation as in the present research: Paths and goals are blocked and movements of feet and hands have to be adjusted. However, loss of self-control while driving a car could have dangerous and potentially fatal consequences.

\section{Acknowledgements}

We thank Sibilla Pencik and Ulli Jahnke for acting as con- federates.

\section{REFERENCES}

Baumeister, R. F. (2002). Ego depletion and self-control failure: An energy model of the self's executive function. Self and Identity, 1, 129-136.

Baumeister, R. F., Bratslavsky, E., Muraven, M., \& Tice, D. M. (1998). Ego depletion: Is the active self a limited resource? Journal of Personality and Social Psychology, 74, 1252-1265.

Baumeister, R. F., DeWall, C. N., Ciarocco, N. J., \& Twenge, J. M. (2005). Social exclusion impairs self-regulation. Journal of Personality and Social Psychology, 88, 589-604.

Baumeister, R. F., Heatherton, T. F., \& Tice, D. M. (1994). Losing control: How and why people fail at self-regulation. San Diego, CA: Academic Press.

Baumeister, R. F., Vohs, K. D., \& Tice, D. M. (2007). The strength model of self-control. Current Directions in Psychological Science, 16, 351-355.

Cohen, S., \& Spacapan, S. (1978). The aftereffects of stress: An attentional interpretation. Environmental Psychology and Nonverbal Behavior, 3, 43-57.

DeWall, C. N., Baumeister, R. F., Gailliot, M. T., \& Maner, J. K. (2008). Depletion makes the heart grow less helpful: Helping as a function of self-regulatory energy and genetic relatedness. Personality and Social Psychology Bulletin, 34, 1653-1662.

Finkel, E. J., Campbell, W. K., Brunell, A. B., Dalton, A. N., Scarbeck, S. J., \& Chartrand, T. L. (2006). High-maintenance interaction: Inefficient social coordination impairs self-regulation. Journal of Personality and Social Psychology, 91, 456-475.

Glass, D. C., \& Singer, J. E. (1972). Urban stress: Experiments on noise and social stressors. New York: Academic Press.

Heller, J. F., Groff, B. D., \& Solomon, S. H. (1977). Toward an understanding of crowding: The role of physical interaction. Journal of Personality and Social Psychology, 35, 183-190.

Langer, E. J., \& Saegert, S. (1977). Crowding and cognitive control. Journal of Personality and Social Psychology, 35, 175-182.

Muraven, M., \& Baumeister, R. F. (2000). Self-regulation and depletion of limited resources: Does self-control resemble a muscle? Psychological Bulletin, 126, 247-259.

Muraven, M., Collins, R. L., \& Nienhaus, K. (2002). Self-control and alcohol restraint: An initial application of the self-control strength model. Psychology of Addictive Behaviors, 16, 113-120.

Muraven, M., Tice, D. M., \& Baumeister, R. F. (1998). Self-control as limited resource: Regulatory depletion patterns. Journal of Personality and Social Psychology, 74, 774-789.

Richeson, J. A., \& Shelton, J. N. (2003). When prejudice does not pay: Effects of interracial contact on executive function. Psychological Science, 14, 287-290.

Schopler, J., \& Stockdale, J. E. (1977). An interference analysis of crowding. Environmental Psychology and Nonverbal Behavior, 1, 81-88.

Stroop, J. R. (1935). Studies of interference in serial verbal reactions. Journal of Experimental Psychology, 18, 643-662.

Vohs, K. D., Baumeister, R. F., \& Ciarocco, N. J. (2005). Self-regulation and self-presentation: Regulatory resource depletion impairs impression management and effortful self-presentation depletes regulatory resources. Journal of Personality and Social Psychology, 88, 632-657.

Vohs, K. D., \& Faber, R. J. (2007). Spent resources: Self-regulatory resource availability affects impulse buying. Journal of Consumer Research, 33, 537-547.

Wallace, H. W., \& Baumeister, R. F. (2002). The effects of success versus failure feedback on further self-control. Self and Identity, 1, $35-42$. 